\title{
Design Concept of a Model Can-sized Sub-orbital Satellite
}

\author{
Ekansh Pradhan*, Aman Dadheech*, Himanshu Agarwal*, Taruna Singh** and Ranganath M. Singari** \\ *Department of Mechanical Engineering, Delhi Technological University, New Delhi, India \\ **Department of Design, Delhi Technological University, New Delhi,, India \\ Corresponding Author: ekansh.pradhan@gmail.com
}

\begin{abstract}
Advancements in technology in the fields of satellite and aerospace systems and the need for smaller yet efficient designs have paved the way for further research into nano and pico-satellites. Smaller systems can prove to be more economical in investigating and measuring various parameters of the atmosphere in a localized area. This paper aims to demonstrate the design of one such system. A can-sized satellite (CanSat) has been designed with respect to the restrictions imposed by the CanSat Competition 2020. The design is developed in a way that allows it to be lightweight without compromising structural integrity. The manufacturing technique aimed to be used is 3D printing using Polylactic Acid (PLA) which allows for greater flexibility in customization and ease of fabrication. The application areas of the model satellite range from space exploration to weather forecasting.
\end{abstract}

Keyword s : 3D printing; Aerospace system; CanSat; Delta wing glider; Sub-orbital satellite

\section{INTRODUCTION}

A satellite of a planet may be defined as any object that travels in an elliptical orbit around that planet (Everett et al., 2018). Satellites are generally divided into two categories: natural and artificial. This paper refers to the design considerations and analysis of a can-sized suborbital satellite for the CanSat Competition (CanSat Competition, 2020) 2020 .

Satellite technology is an ever-evolving field and is used by mankind in areas such as remote sensing, earth observation, space explorations, communications, navigation, and military defense, to name a few (Maini \& Agrawal, 2011). The CanSat Competition is a design-build-fly competition providing teams with an opportunity to experience the design-life cycle of an aerospace system. In the past the competition has included systems such as gyroscopes, heat shields, and payload protection. The competition is continuously evolving with varying problem statements each year in order to encourage students to tackle different problems in the field of aerospace and satellite technology.

In 2019, the competition required design of a delta wing glider (payload), housed within a container, capable of sensing, recording, and transmitting real-time telemetry data during its descent in a helical path. After being launched by an amateur rocket to a height of approximately 700 metres, the payload is deployed at an altitude of about 400 metres and descends at $20 \mathrm{~ms}-1$ in a helical path of radius 250 metres for a minute. The payload is required to land safely using a parachute deployed 100 metres from the ground. Continuous transmission of data packets is required to a ground station throughout the flight of the payload until landing. This study analyses and describes innovative designs in compliance with the competition rules, resulting in a robust satellite equipped with necessary subsystems for real-time telemetry data communication. Figure 1, below, demonstrates the system concept of operations during the launch, deployment, and descent phases of the competition. 


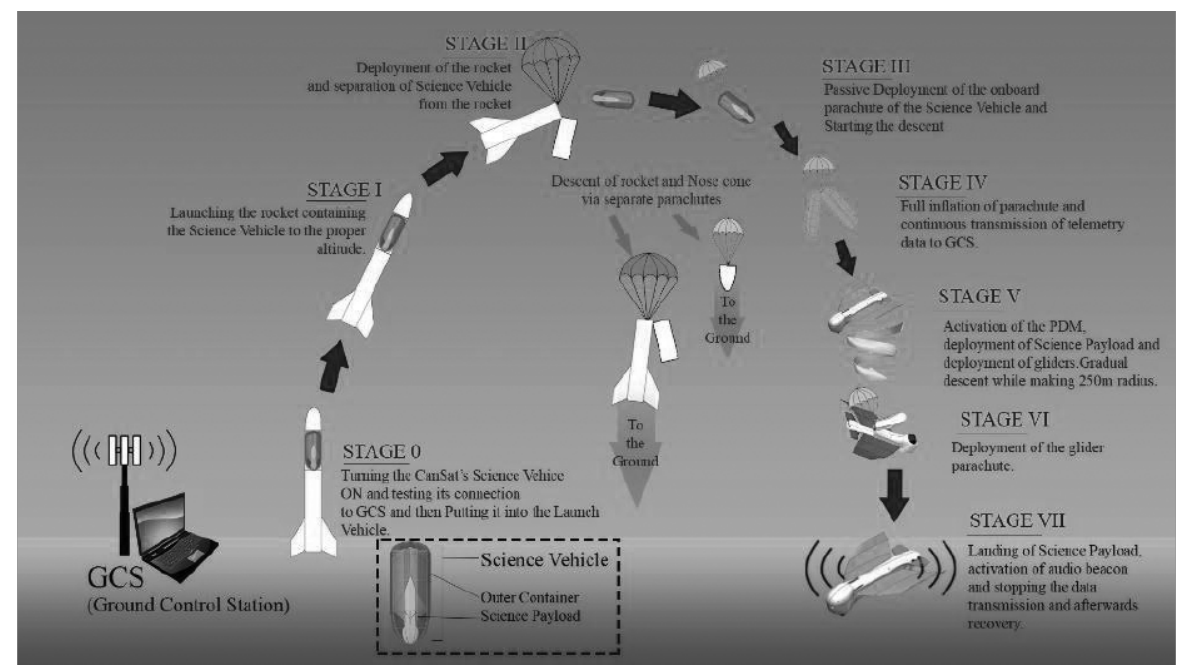

Figure 1. System Concept of Operations

The payload is designed in order to satisfy all the requirements of the competition. The satellite is designed to be lightweight without compromising on structural integrity, withstanding shocks ranging from 10 to $30 \mathrm{G}$ 's. All the components are designed to maintain their functionality at temperatures of approximately 60 degrees Celsius and maintain their mounting integrity at vibrations of $233 \mathrm{~Hz}$.

\section{CANSAT DESIGN OVERVIEW}

\section{Fabrication}

The entire CanSat design has been developed using SolidWorks software. The design is restricted within the limitations imposed by the CanSat Competition 2020. The container is made using aluminium 1060 alloy and the glider is to be 3D printed using PLA (polylactic acid). The complete delta wing glider design weighs approximately 580 grams. The glider is housed within a container that is approximately $300 \pm 10 \mathrm{~mm}$ and has a diameter of $120 \pm 5 \mathrm{~mm}$. The delta wing glider itself has a length of $280 \mathrm{~mm}$ and a width of $204.6 \mathrm{~mm}$ during the deployed state.

As per competition guidelines, the glider is designed to withstand shocks up to 30Gs and provides functionality in temperatures up to $\sim 60{ }^{\circ} \mathrm{C}$. Additionally, no electronics are included within the container itself. All necessary sensors, circuitry, and a power source are located within the glider itself. The glider is hence equipped with necessary mechanisms to deploy, glide, and land safely. Various component designs have been discussed in the following subsections. Tables 1 and 2 summarize the various attributes of the container and the science payload respectively. 
Table 1. Container attributes and component details

\begin{tabular}{|c|c|}
\hline Attribute/Component & Details \\
\hline Container material & $\begin{array}{c}\text { Aluminium } 1060 \text { alloy, wireframe } \\
\text { structure }\end{array}$ \\
\hline Container shape & $\begin{array}{c}\text { Cylindrical body with ellipsoidal bottom } \\
\text { and top, }\end{array}$ \\
\hline Dimensions & $\begin{array}{c}300 \pm 10 \mathrm{~mm} \text { in length, } 120 \pm 5 \mathrm{~mm} \\
\text { maximum diameter }\end{array}$ \\
\hline Descent control strategy & $\begin{array}{r}\text { No active control for descent } \\
\text { Parachute }\end{array}$ \\
\hline
\end{tabular}

Table 2. Science payload and component details

\begin{tabular}{|c|c|}
\hline Attribute/Component & Details \\
\hline Science payload & Delta wing glider \\
\hline Material & 3D printed using PLA \\
\hline Dimensions & $\begin{array}{c}280 \mathrm{~mm} \text { in length, 204.6mm width } \\
\text { (deployed state) }\end{array}$ \\
\hline Descent control strategy & $\begin{array}{c}\text { Active control using foldable wings and } \\
\text { active control surfaces present at the rear }\end{array}$ \\
\hline Parachute & $\begin{array}{c}\text { Dome shaped ripstop nylon parachute, } \\
\text { with spillhole, no vents present. }\end{array}$ \\
\hline
\end{tabular}




\section{Material Selection and Manufacturing Techniques}

Material. The CanSat is required to be robust and survive severe $\mathrm{G}$ forces and temperatures during the turbulent launch and deployment. Consequently, the material of the body should be such that it should have a high tensile strength and abrasion resistance. The constraints imposed on the budget by the competition require us to opt for economical materials and techniques. Additionally, the material should be chemically and electrically inert in order to prevent any unwanted noise or reactions. The materials that best fit the needs for our fabrication process are polylactic acid (PLA) and acrylonitrile butadiene styrene (ABS) (Hafsa et al., 2013). Both these materials have been compared and PLA has been chosen as the material to fabricate the CanSat. Table 3, below, shows the comparisons between the properties of the aforementioned materials (Gutierrez, 2020; Rogers, 2015; Dielectric Manufacturing, 2020).

Table 3. Comparison between various properties of PLA and ABS

\begin{tabular}{|c|c|c|}
\hline Properties & PLA & ABS \\
\hline Density $Q(\mathrm{Mg} / \mathrm{m})$ & 1.25 & $1.01-1.21$ \\
\hline Young's Modulus E $(\mathrm{GPa})$ & 3.5 & $1.1-2.9$ \\
\hline Melting (softening) temperature Tm $\left({ }^{\circ} \mathrm{C}\right)$ & & $88-128$ \\
\hline Tensile Strength ots (MPa) & $36-55$ & $25-50$ \\
\hline Strength to weight ratio & & \\
\hline
\end{tabular}


Table 4. Printing parameters for the generation of gcode

\begin{tabular}{|c|c|}
\hline Specifications & Value \\
\hline Layer Height & $0.2 \mathrm{~mm}$ \\
\hline Wall Thickness & $1.2 \mathrm{~mm}$ \\
\hline Top/Bottom Thickness & $0.8 \mathrm{~mm}$ \\
\hline Infill Density & $50 \%$ \\
\hline Infill Pattern & Trapezoidal \\
\hline Printing Temperature & $210^{\circ} \mathrm{C}$ \\
\hline Build Plate Temperature & $60{ }^{\circ} \mathrm{C}$ \\
\hline Enable Retraction & Yes \\
\hline Print Speed & $50 \mathrm{~mm} / \mathrm{s}$ \\
\hline Enable Print Cooling & Yes \\
\hline Fan Speed & $100 \%$ \\
\hline Generate Support & Yes \\
\hline Build Plate Adhesion Type & None \\
\hline
\end{tabular}




\section{Delta Wing Glider (science payload)}

The delta wing glider is the main component of the satellite system. It includes all electronic components, power systems, and mechanisms in order to ensure that the mission is carried out as per the requirements of the competition. All sensors are located in separate compartments within the glider itself and a latch is provided for quick access to the power source. A parachute is provided which deploys at approximately 100 metres from the ground ensuring a safe landing.

The glider body is designed to be aerodynamic and is equipped with foldable wings that are designed as per NACA 1305 airfoil (Bachuta et al., 2012; Lyu et al., 2014). The wings consist of two sections that are connected via a hinge and are deployed passively using torsion springs. N40 neodymium magnets and steel plates are used between the wing sections to hold them in the deployed phase (Demircali and Uvet, 2018). Servo actuated control surfaces are located at the rear of the glider in order to provide active control during the descent. An exploded view of the delta wing glider is demonstrated below in Figure 2.

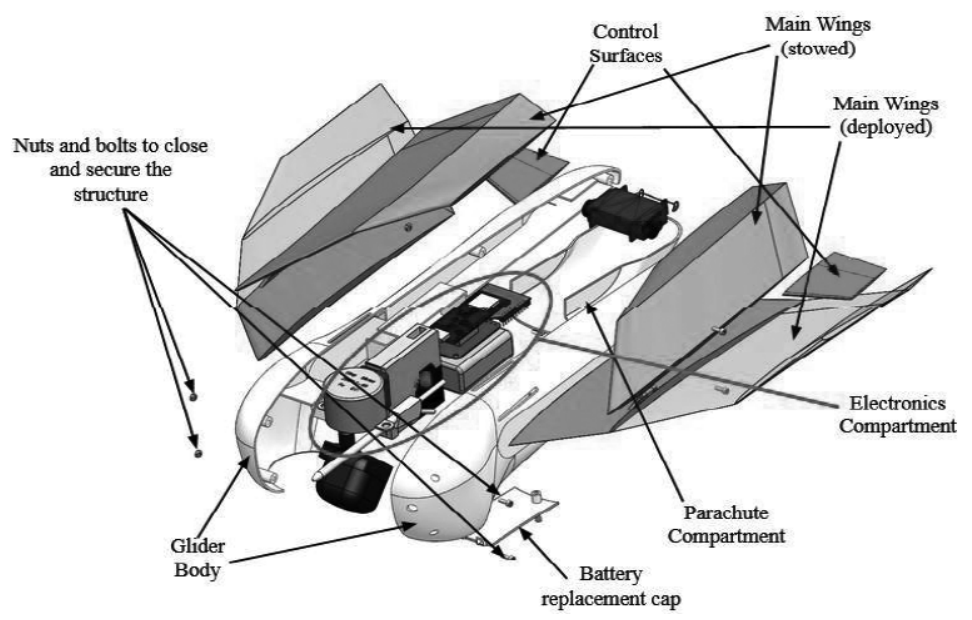

Figure 2. Exploded view of delta wing glider

\begin{tabular}{|c|c|}
\hline Attribute/Component & Details \\
\hline Material & Aluminium 1060 alloy \\
\hline Shape & $\begin{array}{c}\text { Wire frame structure, cylindrical body with } \\
\text { ellipsoidal bottom and top }\end{array}$ \\
\hline Torsion spring & $\begin{array}{c}\text { Force the container to split into two halves } \\
\text { and ensure deployment. }\end{array}$ \\
\hline Guide rails & $\begin{array}{c}\text { Ensure the glider is stowed without being } \\
\text { obstructed by the container. }\end{array}$ \\
\hline Neon green polypropylene sheet covering & $\begin{array}{r}\text { Increase visibility and ease of retrieval } \\
\text { post landing. }\end{array}$ \\
\hline
\end{tabular}




\section{SYSTEM OVERVIEW}

\section{Mechanical subsystem}

The mechanical subsystem consists of the container, the delta wing glider, and the payload deployment mechanism.

Delta wing glider. The science payload consists of a delta wing glider and all the sensors mentioned in Table 7. The sensors are placed carefully in separate compartments and the mini FPV camera is located at the front of the glider. The sensor mountings are securely fastened and are provided with foam spacers in order to reduce the jerk and endure launch accelerations of up to $15 \mathrm{Gs}$. A latch has been provided for quick access to the battery and power switch and can be opened using a single screw. All electrical components have been placed optimally within the container to ensure even mass distribution in the layout.

Payload deployment mechanism (PDM). The payload deployment mechanism, Figure 4, is responsible for ensuring timely and effective deployment of the delta wing glider. The glider is supposed to be deployed at an altitude of about 450 metres. The mechanism designed makes use of fishing cords, nichrome wires, guide rails, and a torsion spring. The fishing cords are used to attach the glider to the container and the nichrome wires are required to cut through the cords by heating up and melting the cords. After melting, the torsion spring relaxes and splits the container in two equal halves. The guide rails make sure that the glider does not get stuck within the cage-like structure of the container. This mechanism reduces the chances of failure during deployment. Table 6 provides a summary of the various components of the payload deployment mechanism and their respective functionality.

Table 6. Payload Deployment Mechanism Component Functions

\begin{tabular}{|c|c|}
\hline Component & Function \\
\hline Fishing cords & $\begin{array}{c}\text { Attach the payload to the container and } \\
\text { maintain stowed condition. }\end{array}$ \\
\hline Nichrome wires & $\begin{array}{c}\text { Heat at } \sim 470 \text { m and melt fishing cords } \\
\text { for deployment. }\end{array}$ \\
\hline Torsion spring & $\begin{array}{c}\text { Force the container to split into two } \\
\text { halves and ensure deployment. }\end{array}$ \\
\hline
\end{tabular}



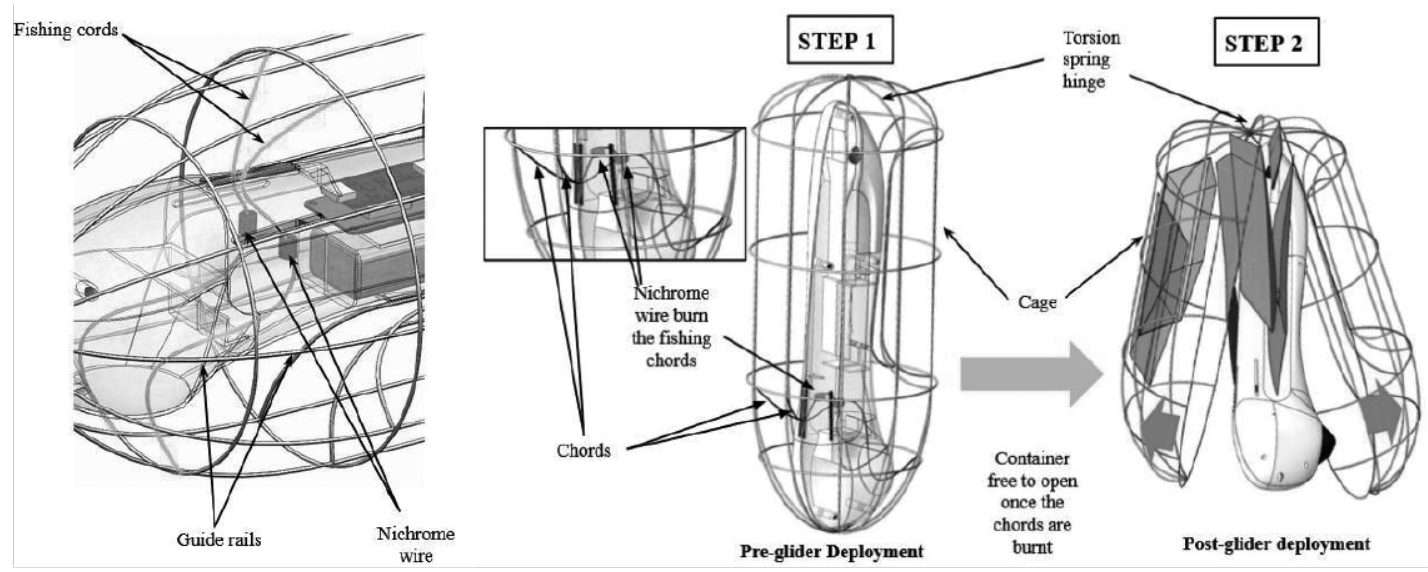

Figure 4. Demonstration of the payload deployment mechanism.

\section{Electrical Subsystem}

Electrical Diagram. Electrical system is required in the CanSat for flight control, communication and data handling, and landing. While choosing the electrical system, various mission requirements needed to be considered. The electrical architecture of the CanSat includes all sensors listed in Table 7, a microcontroller, servo motors and drivers, battery, mini FPV camera, and all the necessary circuitry. A Nickel-metal Hydride (NI/MH) battery was used as the source of energy to power up all these electronics. This has the energy density approaching that of a lithium-ion battery and can have two to three times the capacity of an equivalent size Ni-Cd battery. The camera, particulate matter sensor and the servo motors are supplied with $5 \mathrm{~V}$. All the other sensors, microcontroller and transmitter/receiver modules are supported by 3.3V. Besides this, a voltage divider is present to measure the voltage level of the battery through the analog pins of the processor (Bulut et al., 2013). All these components and their placements are shown below in Figure 5.

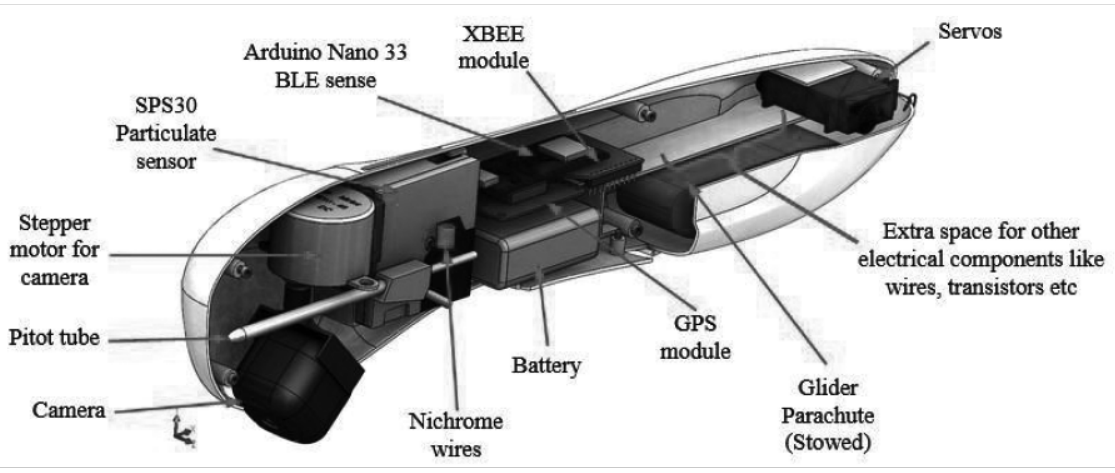

Figure 5. Cross section of glider demonstrating placement of electronic components. 
Table 7. Selected sensors and functions

\begin{tabular}{|c|c|c|c|}
\hline $\begin{array}{c}\text { Serial } \\
\text { No. }\end{array}$ & $\begin{array}{l}\text { Component } \\
\text { Requirement }\end{array}$ & Selected Component & Function \\
\hline 1. & $\begin{array}{l}\text { Air temperature and } \\
\text { Pressure sensor }\end{array}$ & $\begin{array}{l}\text { MPL3115A2 (Adafruit } \\
\text { Industries, n.d.) }\end{array}$ & $\begin{array}{l}\text { Measurement of the air } \\
\text { temperature and air pressure } \\
\text { at payload's position }\end{array}$ \\
\hline 2. & GPS Sensor & $\begin{array}{c}\text { Adafruit - } 746 \\
\text { Ultimate GPS } \\
\text { Breakout (Adafruit } \\
\text { Industries, n.d.) }\end{array}$ & $\begin{array}{c}\text { Determination of the location } \\
\text { of payload - longitude, } \\
\text { latitude and altitude }\end{array}$ \\
\hline 3. & $\begin{array}{l}\text { Payload Power } \\
\text { Voltage Sensor }\end{array}$ & Arduino ADC & $\begin{array}{l}\text { Measurement of the battery } \\
\text { voltage of the payload }\end{array}$ \\
\hline 4. & Airspeed Sensor & $\begin{array}{c}\text { MS4525DO } \\
\text { (TE Connectivity, 2020) }\end{array}$ & To measure air speed \\
\hline 5. & $\begin{array}{l}\text { Particulate Matter } \\
\text { Sensor }\end{array}$ & SPS30 (Sensirion, 2020) & $\begin{array}{l}\text { To determine the amount of } \\
\text { particulate matter in air }\end{array}$ \\
\hline
\end{tabular}

\section{CONCLUSION}

In this paper, a concept model of a can-sized sub-orbital satellite system has been discussed. The design of the delta wing glider (science payload) has been developed under the constraints posed by the CanSat Competition 2020 and measures the particulate matter in the air along with other conditions such as air temperature and pressure during its descent. The mechanical, electrical, and software subsystems, as well as other mechanisms of this aerospace system have been made analogous to a model satellite. Model CanSats may be used to predict weather conditions in disaster prone areas (Chodkaveekityada, 2018), used in space science to measure magnetic fields, concentration of oxygen in the atmosphere, etc. and can be used to track other environmental factors. This design may be used as a stepping stone for people who would like to conduct a practical study in the design of an aerospace system such as a satellite. 


\section{REFERENCES}

Bachuta, M., Czyba, R., Janusz, W., \& Yurkevich, V. 2012. UAV glider control system based on dynamic contraction method. In 2012 17th International Conference on Methods \& Models in Automation \& Robotics (MMAR). Miedzyzdrojie, Poland; IEEE. Retrieved 20 November 2020, from https://doi.org/10.1109/MMAR.2012.6347933.

Bulut, S., Gul, M., Beker, C., Ipek, I., Koculu, O., \& Topaloglu, C. et al. 2013. Model satellite design for CanSat Competition. In 2013 6th International Conference on Recent Advances in Space Technologies (RAST). Istanbul, Turkey; IEEE. Retrieved 20 November 2020, from https://doi.org/10.1109/RAST.2013.6581344.

CanSat Competition. 2020. CanSat Competition Guide 2020 Mission: Delta Wing Glider. Retrieved 20 November 2020, from http://www.cansatcompetition.com/docs/CanSat_Mission_Guide_2020.pdf.

Chodkaveekityada, P. 2018. CanSat design and their applications. In 2018 SpaceOps Conference. Marseille, France; AIAA. Retrieved 20 November 2020, from https://doi.org/10.2514/6.2018-2407.

Demircali, A., \& Uvet, H. 2018. Mini Glider Design and Implementation with Wing-Folding Mechanism. Appl. Sci., 8(9), 1541. https://doi.org/10.3390/app8091541

Dielectric Manufacturing. 2020. Material Properties of ABS - Acrylonitrile-Butadlene-Styrene. Dielectric Manufacturing. Retrieved 20 November 2020, from https://ielectricmfg.com/knowledge-base/abs/.

Digi. n.d. Digi XBee-PRO 900HP RF Module. Digi.com. Retrieved 20 November 2020, from https://www.di gi.com/products/embedded-systems/digi-xbee/rf-modules/sub-1-ghz-rf-modules/xbee-pro-900hp.

Everett, D., Wertz, J., Puschell, J. and Apgar, H. 2018. Space Mission Engineering. Microcosm Press, Torrance.

Gutierrez, R. 2020. PLA Plastic/Material: All You Need to Know in 2020. Retrieved 20 November 2020, from https://all3dp.com/1/pla-plastic-material-polylactic-acid/.

Hafsa, M. N., Ibrahim, M., Wahab, Md.S., \& Zahid, M. S. 2013. Evaluation of FDM Pattern with ABS and PLA Material. Applied Mechanics and Materials, 465-466, 55-59. https://doi.org/10.4028/www.scientif ic.net/amm.465-466.55

Lyu, Z., Kenway, G., \& Martins, J. 2014. Aerodynamic Shape Optimization Investigations of the Common Research Model Wing Benchmark. AIAA Journal, 53(4). https://doi.org/10.2514/1.J053318

Maini, A. K., \& Agrawal, V. 2011. Satellite technology: Principles and applications (2nd ed.). John Wiley \& Sons, Chichester. 